\section{NEJAT SEFERCIOĞLU*}

Kaytaz-zâde Nâzım'ın "Rûh-ı Mecrûh"unda Mevlânâ ve Mevlevîlik

\author{
Mavlana and Mavlawi in a Book Named Ruh-i \\ Macruh of Kaytaz-zada Nazım
}

\section{Ö Z E T}

1857 yılında Lefkoşe'de doğan ve 1924 yılında hayata gözlerini yuman Kaytaz-zâde Mehmed Nâzım Efendi, Kıbrıs'in yetiştirdiği önemli bir şahsiyet ve dîvan tarzında şiirler yazmış bir şâir ve ediptir. Kaytaz-zâde'nin, Harid Fedâi ve Bekir Azgın tarafindan Rûh-ı Mecrûh adıyla yayımlanan şiirleri dışında Yâdigâr-ı Muhabbet ve Leyle-i Visâl adlı iki romanı ile Safâ yahut Netîce-i İbtilâ adını taşıyan bir de tiyatro eseri vardır. Kaytaz-zâde Mehmet Nâzım'ın Rûh-ı Mecrûh adlı şiirlerinin yer aldı̆̆ı eserinin Bekir Azgin tarafindan yazılan geniş "Önsöz"ünde ve Harid Fedai tarafindan kaleme alınan "Kaytaz-zâde'nin Hayatı, Sanatı" başlı̆̆ını taşıyan incelemesinde, şâirimiz hakkında yeterli ve değerli bilgiler yer almıştır. Biz bu

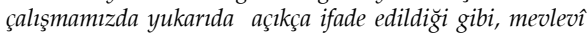
bir şâir olan Kaytaz-zâde Mehmed Nâzım Efendi'nin şiirlerinde yer alan Mevlânâ ve Mevlevîlik'le ilgili manzûme ve beyitleri değerlendirime ğe çalışacă̆ız. Kaytaz-zâde'nin bu beyitlerde Mevlevîlik, Mevlânâ'nın üstün özellikleri ve Mevlevîlikle ilgili unsurlar olarak da Mesnevî, ney, semâ ve Şems-i Tebrîzî̀ye yer verdiğini tespit ettik. Buna göre Mevlevîlik sıkı tutulması gereken bir iptir. Şair Mevlânâ için "Hazret-i Hünkâr", "Hazret-i Monlâ", "Hazret- $i$ Monlâ-yı Rûm", "Mürşîd-i Rûm", "Pîr", "Dergâh- 1 Pîr" ve "Şeh" gibi terkip ve kelimeleri kullanmıştır. Bu hitaplarm hepsi de Mevlânâ'nın olgunluğunu, bilgisini ve inançlarım ifâdeye uygun, Mevlânâ için çok kullanılan hitap şekilleridir. Mesnevî bir hikmet hazinesidir. Nay $\hat{a}$ şı̆̆ın benzetilenidir. Sema' Mevlevîlerin ayinidir. Şems-i Tebrizî şair için kurtarıcı bir mürşittir.

A N A H T A R K E L İ M E L E R

Kaytaz-zade Mehmed Nâzım, Mevlana, Mevlevi, Mesnevi, nay, sema, Şems-i Tebrizî, Lefkoşe..

\section{A B S T R A C T}

Kaytaz-zada Mehmed Nazim Efendi, was born in 1857 in Nicosia-Cyprus and died in 1924, is a importand figure and poet written poems with style of classical Turkish poetry and man of letters. Kaytaz-zada has got two novels named "Yadigar-i Muhabbat" and "Layla- $i$ Visal", also has got a drama named "Safa yahut Netice- $i$ Ibtila", except the poets that are published as the name "Ruh-l Macruh" by Harid Fedai and Bekir Azgin. Enough and valuable knowledge is given in the "preface" written to "Ruh-i Macruh" that contains the poems of Kaytaz-zada Mehmed Nazim, by Bekir Azgin and in the study titled "Kaytaz-zada's Life and Art" written by Harid Fedai. We are going to try to evaluate the poems and verses about Mavlana and Mavlawi that are involved in the poems of a Mavlawi poet, Kaytaz-zada Mehmed Nazim as pointed at above. We've proved in these verses that Kaytaz-zada has included Mesnevi, nay, sema, and Şams-i Tabrizi as Mavlawi, the elements of Mavlawi and the superior characteristics of Mavlana. According to this, Mavlawi is a rope that has to be held hardly. Poet has used the phrases and words "Hazrat-i Hunkar", "Hazrat-i Monla", "Hazrat-i Monla-yı Rum", "Murshid-i Rum","Pir", "Dargah-i Pir", and "Shah" for Mavlana. All these phrases are suitable to express the knowledge, beliefs and the maturity of Mavlana, and most used phrases for Mavlana. Mesnevi is a treasure of wisdom. Nay is compared with lover. Sema is the ritual of Mavlawis. Şams-i Tabrizi is a rescuer mentor for poet..

$$
\text { K E Y W O R D S }
$$

Kaytaz-zada Mehmed Nazim, Mavlana, Mavlavi, Mesnevi, nay, sema, Şams-i Tabrizi, Nicosia..

1857 yılında Lefkoşe'de doğan ve 1924 yılında hayata gözlerini yuman Kaytaz-zâde Mehmed Nâzım Efendi, Kıbrıs'ın yetiştirdiği önemli

\footnotetext{
"Doç. Dr., Girne Amerikan Üniversitesi Eğitim Fakültesi Türkçe Öğretmenliği Bölümü, Kıbrıs (nejatsefercioglu@hotmail.com).
} 
bir şahsiyet ve dîvan tarzında şiirler yazmış bir şâir ve ediptir. Kaytazzâde'nin, Harid Fedâi ve Bekir Azgın tarafından Rûh-ı Mecrûh (1993) adıyla yayımlanan şiirleri dışında Yâdigâr-ı Muhabbet ve Leyle-i Visâl adlı iki romanı ile Safâ yahut Netîce-i İbtilâ adını taşıyan bir de tiyatro eseri vardir.

Kaytaz-zâde Mehmet Nâzım'ın Rûh-ı Mecrûh adlı şiirlerinin yer aldığı eserinin Bekir Azgın tarafından yazılan geniş "Önsöz"ünde (1993: xi-xx) ve Harid Fedai tarafından kaleme alınan "Kaytaz-zâde'nin Hayatı, Sanatı" başlığını taşıyan incelemesinde (1993: xxi-xxix), şâirimiz hakkında yeterli ve değerli bilgiler yer almıştır. Bizim bu çalışmamızın konusu Kaytaz-zâde Mehmed Nâzım Efendi'nin hayatı ve eserleri değildir. Bekir Azgın, Kaytaz-zâde'nin torunlarından Nefi Ünkan'dan aktardığ1 ve sahaflarda çekilen bir fotoğrafın arkasında yer aldığını belirttiği ve "Hazret-i Monlâ-yı Rûm'un bendesi Nâzım gibi, resmi (de) derviş kardeşlerimde yâdigâr kalsın" dediği

Hazret-i Monlâ-yı Rûm'un bendesi Nâzım gibi

Resmi dervişâne ihvânımda kalsın yâdigâr (1993: vii)

beytine yer vermiştir. Biz bu çalışmamızda yukarıdaki beyitte açıkça ifade edildiği gibi, mevlevî bir şâir olan Kaytaz-zâde Mehmed Nâzım Efendi'nin şiirlerinde yer alan Mevlânâ ve Mevlevîlik'le ilgili manzûme ve beyitleri değerlendirmeğe çalışacağız. Kaytaz-zâde'nin bu beyitlerde Mevlevîlik, Mevlânâ'nın üstün özellikleri ve Mevlevîlikle ilgili unsurlar olarak da Mesnevî, ney, semâ ve Şems-i Tebrîzî́ye yer verdiğini tespit ettik.

\section{Mevlevîlik}

Mevlevîlik, büyük mutasavvıf, şâir Mevlânâ Celâleddin-i Rûmî'nin, sevgi ve hoşgörüye dayanan ve temelinde İslâmî inançların yer aldığ görüşlerinin, ölümünden sonra oğlu Sultan Veled tarafından sistemleştirilmesiyle ortaya çıkmış bir tarîkattir. Anadolu insanı için gerçek bir felâket ve yok olma tehlikesinin yaşandığı XIII. yüzyılda ortaya çıkan Mevlevîlik, umutlarını yitirme noktasına gelmiş insanlara umut aşılayan, mâneviyâtlarını yükselten ve felâketlere direnme gücü aşılayan bir 
güç kaynağ1 olmuştur. Bunun sebebi Mevlevîliğin temel prensipleri olan birlik ve beraberlik, hoşgörü ve barış düşüncesidir. Tarîkatın kaynağı şeriat, yani Kur'ân-ı Kerîm'dir. Ne hazindir ki hem tarîkat, hem şerîat kavramlarının içi, bu kavramların gerçek anlamlarını kavrayamayan ya da çarpık menfaatlerine âlet etmek için anlamazlıktan gelenler tarafından boşaltılmış ve bugün korkarak telaffuz edilen kavramlar hâline getirilmiştir.

Mevlevîliğe temel olan düşüncelerin sahibi olan Mevlânâ Celâleddîn-i Rûmî, Kur'an-ı Kerîm'e ve Hz. Muhammed'e gönülden bağlı bir mutasavvıf-şâirdir. Onun Mesnevî̀'sinde olduğu gibi, Dîvân-ı Keb̂̀r, Fîhi Mâ Fîh, Mecâlis-i Seb'a adlı eserlerinde, rubâilerinde ve mektuplarında terennüm ettiği ve dile getirdiği düşüncelerinin kaynağı Kur'ân-ı Kerîm ve Hz. Muhammed'in hadîs-i şerifleridir. İnanmışların hayâtına yön veren bu iki önemli kaynağın insanlara telkîn ettiği güzellikler ise sevgi, hoşgörü, birlik ve berâberlik, dürüstlük ve hiçbir riyâ lekesi taşımadan dînî sorumluluklarını yerine getirmek, Yûnus Emre'nin vecîz bir şekilde ifade ettiği gibi "Yaradılanı Yaradan'dan ötürü sevmek"tir.

Mevlâ; tanrı, Allah, efendi, bey, sâhip, velî, sorumlu kişi vb. anlamlara gelir. Mevlevî ve Mevleviyye, Mevlâ (Allah)'ya mensup demektir. Kelimenin diğer anlamı ise, Mevlânâ'nın tarîkati ve bu tarikata mensup kimsedir. Bu sebeple Mevlâî ile Mevlevî kavramları aynı anlamları ifade eder.

Kaytaz-zâde Mehmet Nâzım'ın iki şekilde değerlendirilmesi mümkün olan, müstakil bir beytinde ve bir kıt'asında karşımıza çıkan Mevlevîlik, kavramın anlamlarına uygun olarak, "hem-zebân" ifadesi içinde dil ve "silk-i celîl" terkîbi içinde ip benzetmelerine konu edilmiştir. Kaytaz-zâde'nin, Rûh-ı Mecrûh adlı eserinde yer alan şekliyle, "Ben âşığım, Hazret-i Mevlânâ (Allah)yı pek severim; (çünkü), Hazret-i Mevlânâ'yı bana aynı dili konuşan etti." dediği:

Âşıkım pek severim Hazret-i Mevlânâ'yı

Hem-zebân etti bana Hazret-i Mevlânâ'yı (Beyit/94, s. 183)

şeklindeki beytinde, Mevlânâ ile aynı dili konuşmasını ona bağışlayan Hazret-i Mevlâ (Allah)'yı niçin çok sevdiğini de ifade etmektedir. Şâirin, 
Mevlânâ ile konuştuğu aynı Mevlevîlik, yani Allah'ı sevme, onun birliğine ve benzersizliğine iman etmedir. Ancak, beytin:

Âşıkım pek severim Hazret-i Mevlânâ'yı

Hem-zebân etti bana Hazret-i Mevlâ nâyı

şeklinde olması da mümkündür. Buna karar vermek için metnin eski harflerle yazılmış orijinal şeklini görmemiz gerekir. Beytin orijinalinin bu şekilde olması durumunda ise şâir ile ney arasında, aynı dili konuşmaları bakımından bir ilgi kurulduğu görülür ve birinci mısradaki "Hazret-i Mevlânâ" ifadesinin Allah olarak değil, Mevlânâ olarak değerlendirilmesi gerekir.

Mevlevîliğin sıkı sıkı tutulması ve asla bırakılmaması gereken ulu bir ip (silk-i celîl) olarak vasıflandırıldığı ve "Celâleddin'in ihsân ve lütuflarına kavuştum, onun için, başkalarının kapısına bă̆lanmanın imkânı yoktur. Dedi-koduyu uzatma, O’nun ulu ipinde bende(bağhl)yim; gönlüm, ezelden beri o Şeh(Allah)in fermânının mă̆lubu (boyun eğeni) oldu." şeklinde nesre çevirmeğe çalıştığımız kıt'a ise şöyledir:

Celâleddîn'in oldum mazhar-1 eltâf ü ihsânı Anunçün bâb-1 gayre intisâbın yokdur imkânı

Uzatma kîl ü kâli bendeyim silk-i celîlinde

Ezelden oldu gönlüm ol Şeh'in mağlûb-1 fermânı (Kıt'a/83, s. 172)

Bu kıt'ada Kaytaz-zâde'nin hareket noktası, Mevlevîlik tarîkiyle gerçek sevgiliye yani Allâh'a ulaşmak arzûsudur. "Silk-i celîl" olarak vasıflandırılan mevlevîlikle kastedilen, Allâh'ın emirleri yani Kur'ân-ı Kerîm'dir. Şâir, Allâh'ın ipine sarılırsa gerçek sultana ulaşacağı inancındadır. Şâirin "tâ ezel (Bezm-i elest)den" verdiği söze sâdık kalarak, Şeh'in fermânına boyun eğmesinin sebebi de budur.

\section{Mevlânâ}

Kaytaz-zâde Mehmet Nâzım Efendi, tahlil etmeğe çalıştığımız beyitlerinde Mevlânâ'ya hitap ederken, Hazret-i Mevlânâ dışında "Hazreti Hünkâr", "Hazret-i Monlâ", "Hazret-i Monlâ-yı Rûm", "Mürşîd-i Rûm", "Pîr", "Dergâh-1 Pîr" ve "Şeh" gibi terkip ve kelimeleri kullan- 
mıştır. Bu hitapların hepsi de Mevlânâ'nın olgunluğunu, bilgisini ve inançlarını ifâdeye uygun, Mevlânâ için çok kullanılan hitap şekilleridir. Bu konuda Kaytaz-zâde'yi diğer şâirlerden farklı bir tutum içinde görmüyoruz. Bu hitapların yer aldığı beyitler ise şâirin "Ey Hazret-i Hünkâr! Imdat, bu hasret yetmez mi? Nâzım dahi o mukaddes yerde bulunsun." dediği:

Yetmez mi bu hasret meded ey Hazret-i Hünkâr

Nâzım dahi ol cây-1 mukaddesde bulunsun （Kıt’a/92-4, s. 181)

şeklindeki beyti; “(Ey Nâzım! Hazret-i Monlâ’nın feyzine kavuştuğum (için), inkâr edenler benim ifade tarzımdan anlamıyorlar." şeklinde nesre çevirmeye çalıştı̆̆ımız:

Füyûz-1 Hazret-i Monlâ'ya mazhar olduğum Nâzım

Galat-1 münkirîn fehm itmiyor tarz-1 beyânımdan (G/29-8, s. 63)

beyti; "Hazret-i Monlâ-yı Rûmun bendesi Nâzım gibi beni, sevgilinin önünde hazır cevap ettin." dediği:

Hazret-i Monlâ-yı Rûm'un bendesi Nâzım gibi

Pîş-gâh-1 yârde hâzır-cevâb ettin beni (G/9-6, s. 29)

şeklindeki beyit; "Mürşîd-i Rûm (Anadolu'nun rehberi), Nâzım'a lutufda bulunarak 'Benim sözümün feyzine mazhar olanımsın' demiş." şeklinde nesre çevirebileceğimiz:

Mürşîd-1 Rûm Nâzıma lutfen dimiş

Mazhar-1 feyz-i suhânımsın benim (G/27-6)

şeklindeki beytini; "Sâliklere doğru yolu bulmada yardımcı ancak ney sedâsıdır; (biz de) pîrin dergâhına düşüp, elestin saf ve temiz suyuna gark olduk." dediği:

Sadâ-yı neydir ancak sâlikâna hâdi-i irşâd

Düşüp dergâh-1 pîre gark-1 ezrâk-1 elest olduk (G/38-6, s. 83)

beyti ve "Yüksek irâde tahtının sultanı, cömertlik ve iyilik kaynă̆ı Hazret-i Mevlânâ'dır." şeklinde nesre çevirdiğimiz: 
Şeh-i evreng-i himem Hazret-i Mevlânâ'dır

Menba-1 lutf u kerem Hazret-i Mevlânâ'dır (G/4-1, s. 10)

şeklindeki matla beytidir.

Kaytaz-zâde Nâzım, Mevlânâ ile ilgili beyitlerinde onu, ilmine ve fazîletlerine uygun vasıflandırmalarla dile getirmiştir. Yukarıdaki beyitte ifade edildiği gibi, Hazret-i Mevlânâ, yüksek irâde tahtının sultânı ve aynı zamanda asâletin, cömertliğin ve iyiliğin kaynağıdır. Olgunluk ülkesine, Mevlânâ'nın zâtına benzer biri bu güne kadar gelmemiştir; çünkü şiirin ve kalemin (nesrin) sahibi Hazret-i Mevlânâ'dır:

Gelmemiş zâtı gibi mülk-i kemâlât içre

Sâhib-i nazm u kalem Hazret-i Mevlânâ'dır (G/4-2, s. 10)

Mevlânâ hikmet hazînesinin sahibidir; çünkü onun Mesnevî́si nice hakîkat incisinin dizileriyle doludur:

Mesnevî'sinde nice dürr-i hakîkat meknûn

Mâlik-i genc-i hikem Hazret-i Mevlânâ'dır (G/4-3, s. 10)

Mevlânâ'nın temiz sözleri, Hz. Îsâ'nın ölüleri dirilten nefesi gibi tesirlidir; (çünkü o) melek yaratılışlıların padişâhıdır:

Nutk-1 pâki dem-i Îsâ gibi tesîr eyler

Şeh-i kerrûbî-şiyem Hazret-i Mevlânâ'dır (G/4-4, s. 10)

$\mathrm{O}$, Anadolu'nun ve İran ülkesinin övüncüdür ve bütün cihan halkı onun düşkün birer bendesidir:

Ser-te-ser halk-1 cihân bende-i efkendesidir

Mefhar-1 Rûm u Acem Hazret-i Mevlânâ'dır (G/4-5, s. 10)

İnsan gözü (çeşm-i beşer), onun bir benzerini aslâ görmemiştir, o dünyaya gelişin sırrını bilendir:

Görmemiş mislini âlemde hemân çeşm-i beşer

Vâkıf-1 sırr-1 kadem Hazret-i Mevlânâ'dır (G/4-6, s. 10)

Mevlânâ, elem ve sıkıntıyı ortadan kaldırandır. Kaytaz-zâde'nin samimiyetle ondan yardım isteme arzusu da Mevlânâ'nın bu özelliğinden kaynaklanmaktadır: 
Nâzımâ sen yine ihlâs ile it istimdâd

Def-i renc ü elem Hazret-i Mevlânâ'dır (G/4-7, s. 10)

Mevlânâ aşkı, hürmete lâyık bir aşktır ve bir yola benzer; şâirin şiiri ayaklarına yüz sürmelidir ve hürmetle gidip Mevlânâ'nın aşkının yolunda sürünmelidir:

Hattım hele rû-mâl-i kudûm-i keremindir

Ta'zîm ile varsın reh-i aşkında sürünsün (Kıt'a/92-2, s. 181)

Mevlânâ'nın feyz (ilmi ve irfân)i, her an şâirin gönlünde tecellî eder, şâirin âşıkâne sözlerinin böyle gönül açıcı olmasının sebebi, Mevlânâ'nın feyzinin her an şâirin gönlünde tecellî etmesidir:

Tecellî-sâz olur her lahza dilde feyz-i Mevlânâ

Anunçün güft ü gûy-1 âşıkanem dil-küşâdır hep (G/15-7, s. 33)

Şâirin gönlünde şimşek gibi çakan da Mevlânâ'nın feyzidir. Şâirin şuh yaradılışı (şâirlik gücü)nı görenlerin onu beğenip alkışlamalarının sebebi budur:

Şûhî-i tab'ım gören tahsîn ider Nâzım benim

Berk uran gönlümde âyâ feyz-i Mevlânâ mıdır (G/7-7, s. 17)

Şâirin ifade tarzının bazı inkârcılar tarafından anlaşılmamasının ya da yanlış anlaşılmasının sebebi de şâirin Hazret-i Mevlânâ'nın feyzine mazhar olmasından kaynaklanmaktadır:

Füyûz-1 Hazret-i Mevlânâ'ya mazhar olduğum Nâzım

Galat-1 münkirîn fehm etmiyor tarz-1 beyânımdan (G/29-8, s. 63)

Mevlânâ'nın lütfunun ihsanına kavuşan, yani onun ilim ve irfânıyla tanışan, başka bir kapıya gidemez. Şâirin onun kapısından, mevlevîlikten ayrılamamasının sebebi de budur. Onun gönlü, mevlevîlik yoluyla ulaşacağına inandığı sevgili (Allah)nin fermânına bezm-i ezelde evet demiş ve onun ipi (Mevlevîlik)ne sarılan bir bendesi olmuştur:

Celâleddin'in oldum mazhar-1 eltâf u ihsânı

Anunçün bâb-1 gayre intisâbın yoktur imkânı

Uzatma kîl ü kâli bendeyim silk-i celîline

Ezelden oldu gönlüm ol şehin mağlûb-1 fermânı (Kıt’a/83, s. 172) 
Mevlânâ'nın makâmı, Kaytaz-zâde Nâzım'ın ulaşmak istediği ve hasretini çektiği mukaddes yer (cây-1 mukaddes)dir. Şâir, mukaddes yer ifâdesiyle büyük bir ihtimalle, Hz. Mevlânâ'ya uygun bulduğu ve oraya gittiğine inandığı, Cennet'i kastetmektedir. Şâirin en büyük arzusu, öbür dünyâda da Mevlâna'ya yakın olmakdır ve:

Yetmez mi bu hasret meded ey Hazret-i Hünkâr

Nâzım dahi ol cây-1 mukaddesde bulunsun (K1t'a/92-4)

şeklinde Mevlânâ'dan yardım istemesi bundandır.

Yukarıda, bir başka vesileyle temas ettiğimiz gibi, Mevlânâ'nın temiz olarak vasıflandırılan sözleri, dolayısıyla eserleri, Hz. İsâ'nın en önemli mucizesi olan ve ölüleri diriltme özelliğine sahip olan nefesine benzetilmiştir. Mevlânâ'nın sözleri, mânen ölmüş olanları hayata kavuşturur, hayattan kopmuş olanları hayata bağlar, inanç ve imanlarının yeşermesine sebep olur; çünkü Hz. Mevlânâ melek yaradılışlıların sultanidir:

Nutk-i pâki dem-i Îsâ gibi te'sîr eyler

Şeh-i kerrûbî-şiyem Hazret-i Mevlânâ'dır (G/4-4)

\section{Mesnevî}

Mevlânâ'nın, daha çok "Mesnevî" adıyla tanınan Mesnevî-i Ma'nevî ve Mesnevî̀- $i$ Şerîf adlarıyla karşımıza çıkan eseri, 25618 beyitten meydana gelmiş dînî, tasavvufî ve ahlâkî, didatik bir eserdir. Mevlevîliğe gönül veren müridlere tasavvufu öğretmek amacıyla yazılmış bir eser olmasına rağmen lirik ve âhenkli bir eserdir. Mevlânâ eserini yazarken Şark efsânelerineden, peygamber kıssaları ve evliya menkabelerinden yararlanmış ve hikmet dolu bir eser meydana getirmiştir. Mesnevî́de yer alan hikâyeler ögüt vermek maksadıyla kaleme alınmış ve esere dahil edilmiştir. İngilizce, Almanca, Fransızca ve Urduca gibi dillere çevrilen Mesnevî XVII. yüzyıl dîvan şâirlerinden Nahîfî tarafından da, nazmen Türkçeye tercüme edilmiştir (Önder-Binark-Sefercioğlu: 1973-74).

Kaytaz-zâde Mehmet Nâzım Efendi, şüphesiz kendisinin de ilham kaynağ1 olan Mesnevî̀yi "Hz. Mevlânâ, hikmet hazinesinin sahibidir; (çünkü onun), Mesnevî'sinde nice hakikat incileri dizilmiş." dediği: 
Mesnevîsi'nde nice dürr-i hakîkat meknûn

Mâlik-i genc-i hikem Hazret-i Mevlânâ'dır (G/4-2, s. 10)

beytinde, "hakikat incilerinin dizisi" ve "hikmet hazînesi" olarak vasıflandırılmıştır. İnci-söz, inci dizisi-manzûme benzetmesi dîvan şâirlerinin sıkça kullandığı benzetmelerdir. Bu benzetmelerin hareket noktası değer ve tanzîm edilmedir. Bir dizi inci mısra, iki dizi inci beyt anlaminda kullanılmıştır. Değerli bir taş olan inci dizilerine sahip olmak ise, hazineye sahip olmaktır. Kaytaz-zâde'ye göre Mesnevî, içinde hakîkat incilerinden meydana gelmiş kıymetli kolyelerin, inci dizilerin bulunduğu bir hikmet hazînesidir ve bu hazînenin sahibi de Mevlânâ'dır.

\section{Nây}

Ney, özellikle mevlevîliğe sembol olmuş nefesli sazlardan biridir. İçinde hava (aşk) bulunması, deliklerinin kıgıın demirle yani ateşle dağlanarak açılması, kurumuş kamışının sarı rengi ve inlemeye benzeyen yanık sesiyle ney, dîvan şiirinde âşığın benzetileni olarak karşımıza çıar. Kaytaz-zâde'nin "Sâliklere doğru yolu bulmada yardımoı ancak neyin sedâsıdır (biz de) pîr(Hz. Mevlânâ)in dergâhına düşüp (bezm-i) elestin saf ve temiz suyuna garkolduk." dediği:

Sadâ-yı neydir ancak sâlikâne hâdi-i irşâd

Düşüp dergâh-1 pîre gark-1 ezrâk-1 elest olduk G/38-6, s. 83)

şeklindeki beytinde ney sesi, sâliklere doğru yolu gösteren bir rehber olarak tasavvur edilmiştir. Bu değerlendirme Mevlânâ'nın ilk onsekiz beytini bizzat kendisinin kaleme aldığı Mesnevî́sine:

Bîşnev ez ney şikâyet mî koned

Ez cüdâyîhâ hikâyet mî koned

yani, Nahîfi'nin tercümesiyle:

Dinle neyden kim şikâyet etmede

Ayrılıklardan hikâyet etmede

diye başlamasındaki gerekçeye de uygun düşmektedir. 
Ney, sesinin rehbere benzetildiği beyit dışında, bir beyitte şâirin kendisi için benzetilen olarak kullanılmıştır. Yanık ve hüzünlü ney sesi ile şâir (âşık)in inlemeleri ve âhı arasında kurulan ilgiye dayanan neyâşık benzetmesinin yer aldığı ve "Dem yerine, ney gibi nâle ve ahlar çekeriz; meclisi, ağlama-inleme ve mâtem yerine çeviririz." dediği matla' beyti de şöyledir:

Ney gibi nâle vü âhlar çekeriz dem yerine

Bezmi tahvîl ideriz şîven ü mâtem yerine (Fedai-Azgın 1993: 238)

Ney, yukarıda imlâsının orijinal metinde değişik olması ihtimaline temas ettiğimiz ve bu şekliyle "(Ben) âşı̆̆̆ım (bu sebeple) Hazret-i Mevlânâ'yı pek severim; Hazret-i Mevlâ, neyi bana aynı dili konuşan etti." şeklinde nesre çevirebileceğimiz:

Âşıkım pek severim Hazret-i Mevlânâ'yı

Hem-zebân etti bana Hazret-i Mevlâ nâyı

beyitinde ney, teşhis sanatıyla kişileştirilerek, yazarla aynı dili konuşan bir insan olarak hayâl edilmiştir. Yazarın kendisini âşık yerine koyduğu bu ilgide, neyin yanık, içli sesi ile âşığın inlemelerinin, bir anlaşma vasıtası olan dile benzetilmesi temel unsurdur.

\section{Semâ'}

Semâ', Mevlevî âyinlerinde tarîkat mensuplarının cezbe hâlinde dönerek icra ettikleri ve kendine has usûl ve erkânı olan bir çeşit rakstır. Abdülbâkî Gölpınarlı, semâ'-zenin semâ' yaparken aldığı duruşla ilgili olarak, Mevlânâ'dan sonra Mevlevîlik adlı eserinde "Semâ'a giren, yavaş yavaş kollarını omuzlarından göğsüne doğru sıyırarak indirir ve ellerini çapraz vaziyetten kurtarıp yanlarına getirir. Kanat açar gibi kıvrılan kollarını yavaşça düzelterek her iki kolunu yukarıya doğru kaldırır ve düz bir şekilde açmış olur. Vücûda nisbetle başa doğru yükselmiş olan düz kolların sağ eli, duâ vaziyetinde ve yukarıya doğru açıktır, sol eli aşağ1 doğru sarkar. Baş sağ tarafa eğiktir, yüz tamamiyle sola çevrilmiştir. Gözler kapanır, yahut süzülür ve içten ismi celâl çekilerek semâ' edilirken tennûre de açılır." (1983: 376) şeklindeki bilgileri vermektedir. Kaytaz-zâde'nin "El açarak, ayak vurarak semâ' eder döneriz; aşă̆ıda ve yukarıda oturanlar bize mest ve hayrandır." şeklinde nesre çevirebileceğimiz: 
Dest-efşân pây-kûbân eyleriz devr-i semâ

Sâkinân-1 zîr ü bâlâ mest ü hayrandır bize (G/123-5)

beytinde semâ' yapan bir Mevlevî dervîşinin ulaştı̆̆ı manevî güzelliklere de işaret edilmiştir.

\section{6. Şems-i Tebrîzî}

Mevlâna'nın gönül dostu olan Şems-i Tebrîzî́nin Kaytaz-zâde'nin bir şiirinde yer alışının sebebi, şâirin Şems-i Tebrîzî́yi, pîri Mevlânâ gibi, içine düştüğü mânevî sıkıntılardan ve perişanlıktan kurtaracak bir kurtarıcı olarak görmesidir. "Bu değersiz kalbi felek kırdı, sabah rüzgârı bu hasrete düşmüss selâmımı sevgiliye arz et. Nâzım perî̧̧an oldu, ey Şems-i Tebrîzî gel yetiş. Hâlâ mihnetin esîriyim, selâmet mümkün olmaz mı? Benim ikbâlim kapanmış (kararmış), aydınlığa (güneşin doğuşuna) meyletmez mi?" dediği:

Şikest itdi felek her vechile bu kalb- nâçîzi

Sabâ arz eyle cânâne selâm-ı hasret-âmîzi

Perîşân oldu Nâzım gel yetiş yâ Şems-i Tebrîzî!

Esîr-i mihnetim hâlâ selâmet kâbil almaz mı?

Kapanmış benim ikbâlim tulû́a mâil olmaz mı! (Şarkı/46, s. 97)

mısralarında, şems kelimesinin güneş anlamından da yararlanan şâir, nakarat mısralarında ifade ettiği kararan ikbâlini aydınlatacak, kendisini aydınlığın huzuruna kavuşturacak güneş olarak Şems-i Tebrîzî́yi görmektedir.

\section{Netice}

Kaytaz-zâde Nâzım Efendi, Rûh-ı Mecrûh adlı şiir kitabında yer alan şiirleriyle, elbette ki önemli dîvan şairlerimizle aynı kefeye koyacağımız bir şâir değildir. Bu hem şiirlerinin yapısı hem de şiirlerinin sayısı itibariyle düşünülemez. Kaytaz-zâde Nâzım'ın yaşadığı yılları, Divan edebiyatımız bakımından değerlendirirsek, artık söyleyeceği her şeyi söylemiş, ona hayat veren unsurları zaman içinde tüketmiş bir edebiyatın temsilcisi olmak o kadar kolay bir iş değildir. Değerlerin, görüşlerin ve zevklerin süratle değiştiği, sosyal sıkıntıların ve çalkantılarn yoğun bir 
şekilde yaşandığı bir dönemde bunu başarmak ise, asla kolay bir iş değildir. Bunu Kaytaz-zâde Mehmet Nâzım Efendi'den beklemek ise buyük haksızlık olur. Biz bu çalışmamızda şâirin bu yönünü değerlendirmeyeceğimizi, konuşmamızın başında ifade etmiştik. Kaytaz-zâde'nin incelemeye çalıştığımız Mevlânâ ve mevlevîlikle ilgili sınırlı sayıdaki manzûme ve beyitlerinde samîmî bir Mevlâna âşığı olduğunu ve bu samimiyetini mısralarına aksettirdiğini söyleyebiliriz. Sunduğumuz beyitlerindeki akıcılık ve ifade rahatlığının da bu samimiyetten beslendiğini ifade etmek gerekir. İnançlarının ve duygularının beslediği bu mısraların onun, yaşadığı devre göre, hiç de yabana atılamayacak dîvan şiiri örnekleri olduğunu söyleyebiliriz. Kaytaz-zâde Nazım Efendî'nin her Mevlevî şâir gibi İslâmî inançları sağlam, Hz. Muhammed'e gönülden bağlı ve Hz. Mevlânâ'ya hayran bir kişi olduğu, eserinin başında yer alan yedi beyitlik bir münâcaat (Fedai-Azgın: 1993: 3), biri on, diğeri 9 beyitlik iki na't (Fedai-Azgın 1993: 5-6, 8-9), “Der Vasf-1 Cenâb-1 Mevlânâ" başlıklı yedi beyitlik bir gazel (Fedai-Azgın 1993: 10), biri "Hazret-i Mevlânâ Hakkında Bir Kıt'a", digeri "Hazret-i Pîr-i Dest-gîr Efendimiz İçün Arz-1 İştiyâk" başlıklı iki kıta (Fedai-Azgın 1993: 172, 181), muhtelif gazellerinde yer alan altı beyit (Fedai-Azgin 1993: 17, 29 , 33, 38, 63, 181) ve müstakil beyitten (Fedai-Azgın 1993: 183) anlaşılmaktadır. Ayrıca biri "Âl-i resûl" için yazdığı onbeş beyitlik (Fedai-Azgın 1993: 12-13) ve diğeri Mevlevî şeyhi Safvet Dede için yazdığ1 "Tahassür" başlıklı, nakaratlı şarkı şeklinde kaleme alınmış iki mersiye (Fedai-Azgın 1993: 44-45) ve Şems-i Tebrîzî'nin yer aldığı bir başka şarkı (Fedai-Azgın 1993: 97) da bu konuda bize fikir verecek mahiyette manzûmelerdir.

\section{Kaynaklar}

FEDAİ, Harid-AzGIN Bekir (1993), Kaytaz-zâde Nâzım Efendi: Ruh-ı Mecruh Şiirler-, İstanbul: Boyut Matbaacılık, xlv+253 s.

GÖLPINARLI, Abdülbâki (1983), Mevlânâ'dan Sonra Mevlevîlik, 2. bs., İstanbul: İnkılap ve Aka Kitabevi, 376 s.

ÖNDER, Mehmet-BiNARK, İsmet-SEFERCiOĞLU, Nejat (1973-74), Mevlâna Bibliyografyası 1: Basmalar (Kitap-Makale), 2: Yazmalar, Ankara: Tisa Matbaacılık, xviii+280, 28+323 s. 